\title{
DIVERGÊNCIAS, CONGRUÊNCIAS E RETICÊNCIAS: UMA ANÁLISE COMPARATIVA ENTRE PRODUTOS DOS PROGRAMAS ESCOLA SEM HOMOFOBIA E SAÚDE E PREVENÇÃO NA ESCOLA
}

\author{
Isaias Batista de OLIVEIRA JÚNIOR ${ }^{1}$ \\ Eliane Rose $\mathrm{MAIO}^{2}$
}

RESUMO: Os níveis de desqualificação aos quais milhares de jovens e adultos LGBT são submetidos emergem nas mais diversas instâncias como: igreja, política, mídia, sociedade, escola, etc., A escola caracteriza-se como um local estratégico de implementação de políticas educacionais. Nesse contexto surgem ações como Programa Escola sem Homofobia e Saúde e Prevenção na Escola. Como fragmento de uma pesquisa mais ampla voltada a qualificação de Mestrado, trazemos a discussão os subprodutos advindos desses Programas intitulados: Kit anti-homofobia do MEC e Guia de Adolescentes e Jovens para a Educação entre Pares, respectivamente. Ambas as estratégias apresentam congruências, divergências e reticencias entre si. Para o estudo nos baseamos na acepção dos estudos culturais e no referencial literário produzido sobre a temática, caracterizando a pesquisa bibliográfica. Conclui-se que a ausência de materiais sobre a temática não pode mais ser justificativa para discutir a diversidade sexual e combate e prevenção à homofobia, pois se determinado material não foi distribuído para as escolas, educadores/as podem contar com outras publicações já realizadas.

PALAVRAS-CHAVE: Kit anti-homofobia. Guia de adolescentes e jovens para a educação entre pares. Projeto Escola Sem Homofobia. Diversidade sexual. Homofobia.

\section{Introdução}

As sociedades, inclusive a brasileira, são em sua maior parte constituídas e estruturadas pela (s) diversidade (s), tanto étnica, quanto racial, religiosa, política, cultural, sexual, ideológica, entre outras. São essas diferenças que modulam e estruturam a construção identitária de um coletivo através de processos históricos, sociais e culturais. Nesse aspecto a promoção da cultura do reconhecimento da (s) diversidade (s) representa mais do que um compromisso de ordem ética assumindo um caráter de direito irrenunciável.

Ao nos conscientizarmos de que essa (s) diversidade (s) nos caracteriza como sociedade/indivíduos, somos impelidos a procurar novas formas de configurar um fator

\footnotetext{
${ }^{1}$ Mestre em Educação. UEM - Universidade Estadual de Maringá. Doutorando em Educação. UNESP Universidade Estadual Júlio Mesquita Filho. Faculdade de Ciências e Letras. Araraquara - SP - Brasil. 14800-901 - jr_oliveira1979@hotmail.com

${ }^{2}$ Doutora e Pós-Doutora em Educação Escolar. UNESP - Universidade Estadual Júlio Mesquita Filho. Docente da Universidade Estadual de Maringá, do Departamento de Teoria e Prática da Educação - DTP e do Programa de Mestrado e Doutorado em Educação - PPE. Maringá - PR - Brasil. 87020-900 elianerosemaio@yahoo.com.br
} 
de enriquecimento e de desestabilização de sistemas de representações que estabiliza, hierarquizam e constituem dicotomias normalizantes. Nesse aspecto a afirmação e assunção de um padrão heteronormativo como sendo verdadeiro, natural, previsível e inevitável acaba por estigmatizar as demais manifestações da sexualidade e a(s) identidade (s) assumida (s) por outros sujeitos que desatendem esse processo construtivo baseado no binarismo mulher/homem, macho/fêmea e assumem uma predileção homossexual, como no caso de homens e mulheres Gays, Lésbicas, Bissexuais, Travestis, Transexuais e Transgêneros. A opção/orientação ${ }^{3}$ sexual desses sujeitos tende a ser considerada por muitos atores sociais, como patológica, anormal, pervertida, desviante e condenatória e a eles/as são imputados à abjeção e destinado toda a repulsa, ódio e aversão manifesta através de práticas discriminatórias (HALL, 2007, 2006; SILVA, 2007; JUNQUEIRA, 2007, 2009).

Os níveis de desqualificação aos quais milhares de jovens e adultos LGBT são submetidos, o que chamaremos de LGBTfobia $^{4}$ emergem nas mais diversas instâncias como: igreja, política, mídia, sociedade, escola, etc., através de "[...] ações punitivas ou recuperadoras, de reclusão ou de regeneração, de ordem jurídica, religiosa ou educativa" (LOURO, 2009, p.88). O grau de preconceito ao quais esses sujeitos são expostos variam desde a antilocução, esquiva, discriminação, ataque físico e extermínio, ou seja, coisas reconhecidamente horríveis como matar e/ou espancar, discriminação social e supressão dos direitos, como a coisas bem sutis, quase imperceptíveis, como piadas, estereotipizações, ou imagens negativas, repulsa, isolamento (DOVIDIO; GLICK; RUDMAN, 2005; PINHEIRO, 2012).

\footnotetext{
${ }^{3}$ Brasil (2004), Sayão (1997) e militantes do movimento LGBTT adotam o termo orientação sexual como sendo uma atração afetiva e/ou sexual que uma pessoa sente pela outra. Para Sousa Filho (2013a, 2013b, 2009) aqueles que pensam assim acreditam que é politicamente contraproducente, e torna-se mesmo proibido [!], compreender as chamadas orientações sexuais como escolhas do erotismo, da sensualidade, do desejo, sempre subjetivas e singulares, nem estáveis nem absolutas, e, portanto, que podem ser traduzidas como eleições, opções, preferências do desejo individual. A orientação sexual é uma prática no sentido também que cada um, exercitando-se, experienciando, constrói, menos ou mais conscientemente, sua vida erótica, seu regime de prazeres. Acredita-se que a manifestação da sexualidade é uma orientação sexual, a forma de manifestá-la é uma opção de cada um.

${ }^{4}$ Adotaremos o termo LGBTfobia para sublinhar que a intolerância social em relação à homossexualidade masculina (ideia implícita à noção de homofobia) não é da mesma ordem que a intolerância que atinge lésbicas (oprimidas por uma lesbofobia que, além de homofóbica, é machista e sexista), nem do repúdio que atinge travestis e transexuais, cujas existências ferem de morte os binarismos macho-fêmea, homemmulher, o que as torna vítimas preferenciais do terrorismo de gênero. Adotando essa medida evita-se o uso repetitivo das expressões lesbofobia, transfobia, travestifobia, gayfobia e bifobia, o que cansaria o/a leitor/a e também porque a linguagem é um fator de exclusão e de expressão de preconceitos e que nos obriga a utilizar termos masculinos como signos genéricos referentes a mulheres e homens. (MELLO et al., 2012; AGREDA, 2012; BRASIL, 2011a; DINIS, 2011).
} 
No processo de construção da igualdade de direitos e reconhecimento da (s) identidades (s), principalmente no que se refere à diversidade sexual e combate a LGBTfobia faz-se necessário destacar que desde a década de 1920, a lei brasileira prevê a escola como sendo um, senão o principal, agente de diálogo sobre educação para sexualidade. Tal concepção encontra suporte na elaboração dos Parâmetros Curriculares Nacionais em 1995 e a inclusão da temática orientação sexual, embora sem fazer menção a temática diversidade sexual, subtende-se que aí deveriam estar inclusas questões que envolvam o debate sobre as múltiplas manifestações da sexualidade (SAYÃO, 1997; BORGES; MEYER, 2008).

Como estratégia para suprir essa demanda tem-se assistido na última década um aumento expressivo na consolidação e produção de Programas, Projetos e materiais, que preveem o enfrentamento e combate a violência no âmbito escolar elaborado tanto pela sociedade organizada quanto pelo próprio Estado. Como referência dessas táticas pode citar: o Programa Brasil sem Homofobia (BSH), o Projeto Escola sem Homofobia (ESH) e o Programa Saúde na Escola (PSE).

Para a efetivação dessa análise, transpomos fragmentos de uma pesquisa elaborada para a dissertação de mestrado em educação e que envolve discussões acerca da diversidade sexual, combate e prevenção à homofobia. Portanto colocamos em diálogo a elaboração de estratégias educacionais voltadas ao tratamento da temática denominadas Programa Brasil sem Homofobia que veio a contribuir para a implementação do Projeto Escola sem Homofobia, onde uma das diretrizes propostas pelo projeto culminou com a elaboração do material intitulado kit anti-homofobia e com o Programa Saúde nas Escolas que serviu de fundamentação para a elaboração do Guia de Adolescentes e Jovens para a Educação entre Pares. Buscamos neste diálogo estabelecer as congruências, as divergências e as reticencias apresentadas em ambos os programas, que mesmo sendo de pastas diferentes, possuíam o mesmo objetivo: combater a violência contra alunos/as, jovens e adultos L, G, B e Ts presentes no cotidiano escolar.

Baseamos-nos para a elaboração deste material nos estudos Culturais propostos por Hall (2006, 2007), Silva (2007), Costa, Silveira e Sommer (2003). Para a efetivação da proposta utilizamos um apanhado, sobre os principais trabalhos científicos já realizados, revestidos de importância pela capacidade de fornecerem dados atuais e relevantes, denominado pesquisa bibliográfica. Esse tipo de pesquisa abrange às publicações avulsas, livros, jornais, revistas, vídeos, internet, etc. (LUNA, 1999). 


\section{Congruências}

A palavra congruência possui como definição ato ou efeito de concordar, de coincidir ou de possuir relação direta de uma coisa ou fato com o fim a que se destina. Nessa perspectiva acredita-se que tanto o BSH como o PSE se assemelham em alguns aspectos e comungam dos mesmos objetivos. Como um princípio comum a ambos os programas encontramos o desejo de subversão do caráter hegemônico na produção, classificação e estruturação da (s) identidade (s) e reprodução da (s) diferença (s).

A mais importante forma de classificação quando nos referimos à orientação/opção sexual é aquela que subverte a estabilidade das categorias biológicas e se estrutura ao redor de oposições binárias: masculino/feminino, macho/fêmea, heterossexual/homossexual, (SILVA, 2007; HALL, 2007). A fixação dessa identidade heteronormativa é:

[...] uma das formas privilegiadas de hierarquização das identidades e das diferenças. A normalização é um dos processos mais sutis pelos quais o poder se manifesta e no campo da identidade e diferença. Normalizar significa eleger - arbitrariamente - uma identidade específica como parâmetros em relação ao quais as outras identidades são avaliadas e hierarquizadas. Normalizar significa atribuir a essa identidade todas as características positivas possíveis, em relação às quais as outras identidades só podem ser avaliadas de forma negativa. A identidade normal é tal que ela nem sequer é vista como uma identidade, mas simplesmente como $a$ identidade. Paradoxalmente, são as outras identidades que são marcadas como tais. (SILVA, 2007, p.83, grifos do autor).

Foucault (2004) alega que esse poder normalizador apresenta como base um caráter disciplinar que não visa nem a expiação e nem mesmo a repressão, mas:

[...] põem em funcionamento cinco operações bem distintas: Relacionar os atos, os desempenhos, os comportamentos singulares a um conjunto, que é ao mesmo tempo campo de comparação, espaço de diferenciação e princípio de uma regra a seguir; Diferenciar os indivíduos em relação uns aos outros e em função dessa regra de conjunto que se deve fazer funcionar como base mínima, como média a respeitar ou como o ótimo de que se deve chegar perto; Medir em termos quantitativos e hierarquizar em termos de valor as capacidades, o nível, a "natureza" dos indivíduos; Fazer funcionar, através dessa medida "valorizadora", a coação de uma conformidade a realizar. Enfim traçar o limite que definirá a diferença em relação a todas as diferenças, a fronteira externa do anormal (a "classe vergonhosa"). A penalidade perpétua que atravessa todos os pontos e controla todos os instantes das instituições disciplinares compara, diferencia, hierarquiza homogenia, exclui. Em 
uma palavra, ela normaliza. Opõe-se então termo por termo a uma penalidade judiciária que tem a função essencial de tomar por referência, não um conjunto de fenômenos observáveis, mas um corpo de leis e de textos que é preciso memorizar; não diferenciar indivíduos, mas especificar atos num certo número de categorias gerais; não hierarquizar, mas fazer funcionar pura e simplesmente a oposição binária do permitido e do proibido; não homogeneizar, mas realizar a partilha, adquirida de uma vez por todas, da condenação. Os dispositivos disciplinares produziram uma "penalidade da norma" que é irredutível em seus princípios e seu funcionamento à penalidade tradicional da lei. (FOUCAULT, 2004, p.152-153).

Considerando esses aspectos na perspectiva da "[...] diversidade, a diferença e a identidade tendem a ser naturalizada, cristalizada, essencializada. São tomadas como dados ou fatos da vida social diante dos quais se deve tomar uma posição”. (SILVA, 2007, p.73). E em geral, quando há uma posição aceita socialmente e/ou pedagogicamente, não ultrapassa a mera questão do respeito e da tolerância frente a(s) diversidade (s) e diferença (s).

Nesse sentido e considerando os efeitos danosos das discriminações e desigualdades sociais relativos à diversidade sexual, o Governo Federal através do Plano Plurianual 2004-2007 (BRASIL, 2004b) definiu, no âmbito do Programa Direitos Humanos, Direito de Todos a ação denominada Elaboração do Plano de Combate a Discriminação contra Homossexuais. Este programa possui o intuito de “[...] promover a cidadania e direitos humanos às lésbicas, gays, bissexuais, travestis e transexuais (LGBT) a partir da equiparação de direitos e do combate à violência e à discriminação homofóbicas” (BRANDÃO; SANTANA, 2011, p.167) baseado em ações de:

[...] apoio a projetos de fortalecimento de instituições públicas e não governamentais que atuam na promoção da cidadania homossexual e/ou no combate à homofobia; Capacitação de profissionais e representantes do movimento homossexual que atuam na defesa de direitos humanos; Disseminação de informações sobre direitos, de promoção da autoestima homossexual e; Incentivo à denúncia de violações dos direitos humanos do segmento GLTB. (BRASIL, 2004, p.11).

Pautado e delineado com base nos seguintes princípios básicos o BSH estabelece:

I) inclusão da perspectiva da não discriminação por orientação sexual e de promoção dos direitos humanos de gays, lésbicas, transgêneros e bissexuais, nas políticas públicas e estratégias do Governo Federal, a serem implantadas (parcial ou integralmente) por seus diferentes Ministérios e Secretarias. II) A produção de conhecimento para 
subsidiar a elaboração, implantação e avaliação das políticas públicas voltadas para o combate à violência e à discriminação por orientação sexual, garantindo que o Governo Brasileiro inclua o recorte de orientação sexual e o segmento GLTB em pesquisas nacionais a serem realizadas por instâncias governamentais da administração pública direta e indireta. III) A reafirmação de que a defesa, a garantia e a promoção dos direitos humanos incluem o combate a todas as formas de discriminação e de violência e que, portanto, o combate à homofobia e a promoção dos direitos humanos de homossexuais é um compromisso do Estado e de toda a sociedade brasileira. (BRASIL, 2004, p.11-12).

Em um trabalho multiprofissional o Programa BSH estabelece à articulação no combate à homofobia com as diversas esferas sociais. Compreendemos a relevância de todas as ações previstas pelo Programa "Brasil sem Homofobia", porém cabe nesse momento debater aquelas voltadas para especificamente para a educação, pois a escola é vista como um ambiente propício para propagação dos direitos humanos (ALTMANN, 2001, 2003).

Apoiado pelo Ministério da Educação/Secretaria de Educação Continuada, Alfabetização e Diversidade (MEC/SECAD), surge então o Projeto Escola Sem Homofobia (ESH) com o principal objetivo de contribuir para a implementação do BSH pelo Ministério da Educação (INCLUSIVE, 2011). Além de conter uma série de medidas para combater o preconceito contra a livre escolha sexual, também fazia parte da estrutura do Projeto ESH a distribuição às escolas da rede pública de um chamado "Kit de Combate à Homofobia nas Escolas", também encontrado pelo nome de: "Kit Contra a Homofobia" ou "Kit Anti-homofobia" ou "Kit Gay" (BRANDÃO; SANTANA, 2011, grifos nosso).

O kit anti-homofobia desenvolvido em articulação com a esfera educacional foi planejado e executado pela Global Alliance for LGBT Education (GALE); às ONG Reprolatina (MORÁGUEZ, 2011), Ecos - Comunicação em Sexualidade e Pathfinder do Brasil e a Associação Brasileira de Gays, Lésbicas, Bissexuais, Travestis, Transexuais (ABGLT). Todas as etapas de planejamento e execução do projeto foram debatidas e acompanhadas pelo Ministério da Educação/Secretaria de Educação Continuada, Alfabetização e Diversidade (BRASIL, 2007).

Construído ao longo de dois anos, o kit seria composto por um conjunto de materiais didáticos incluindo: 06 Boleshs (Boletins Escola sem Homofobia), 01 cartaz e 01 carta, 01 Caderno (Escola sem Homofobia) e os Recursos Audiovisuais: Medo de Quê? Boneca na Mochila além de 03 vídeos: Torpedo, Encontrando Bianca e 
Probabilidade. Esses materiais seriam destinados aos/às profissionais da educação e distribuídos para seis mil escolas públicas de ensino médio, a partir do segundo semestre de 2011. Para a preparação do kit anti-homofobia foi demandado um investimento financeiro de aproximadamente 1,8 milhões em convênios que incluía, além da confecção de vídeos e cartilhas para professores/as, pesquisas, seminários e atividades de formação contínua para docentes (MELLO et al., 2012; GATTI, 2003; OLIVEIRA JÚNIOR; LIMA; MAIO, 2012).

Sendo assim, tratava-se de um conjunto de instrumentos didático-pedagógicos com a proposta de desconstrução de imagens estereotipadas sobre lésbicas, gays, bissexuais, travestis, transexuais e transgêneros e para o convívio democrático com a diferença que visava contribuir para:

[...] alterar concepções didáticas, pedagógicas e curriculares, rotinas escolares e formas de convívio social que funcionam para manter dispositivos pedagógicos de gênero e sexualidade que alimentam a homofobia. Promover reflexões, interpretações, análises e críticas acerca de algumas noções que frequentemente habitam as escolas com tal "naturalidade" ou que se naturalizam de tal modo que se tornam quase imperceptíveis, no que se refere não apenas aos conteúdos disciplinares como às interações cotidianas que ocorrem nessa instituição. Desenvolver a criticidade infanto-juvenil [...]. Divulgar e estimular o respeito aos direitos humanos e às leis contra a discriminação em seus diversos âmbitos. (INCLUSIVE, 2011, s/p).

O Programa Saúde na Escola (PSE) fruto de uma parceria entre Ministério da Saúde e do Ministério da Educação, foi instituído em 2007 pelo Decreto Presidencial no 6.286. Resultado do esforço do governo federal em construir políticas intersetoriais para a melhoria da qualidade de vida da população brasileira. Nesse contexto, as políticas de saúde e educação voltadas às crianças, adolescentes, jovens e adultos da educação pública brasileira uniram-se para promover o desenvolvimento pleno desse público (BRASIL, 2011b). Como diretrizes para o seu fortalecimento o PSE estabeleceu:

I) Tratar a saúde e educação integrais como parte de uma formação ampla para a cidadania e o usufruto pleno dos direitos humanos; II) Permitir a progressiva ampliação intersetorial das ações executadas pelos sistemas de saúde e de educação com vistas à atenção integral à saúde de crianças e adolescentes; III) Promover a articulação de saberes, a participação dos educandos, pais, comunidade escolar e sociedade em geral na construção e controle social das políticas públicas da saúde e educação; IV) Promover a saúde e a cultura da paz, favorecendo a prevenção de agravos à saúde, bem como fortalecer a relação entre as redes públicas de saúde e de educação; V) Articular as 
ações do Sistema Único de Saúde (SUS) às ações das redes de educação pública de forma a ampliar o alcance e o impacto de suas ações relativas aos educandos e suas famílias, otimizando a utilização dos espaços, equipamentos e recursos disponíveis; VI) Fortalecer o enfrentamento das vulnerabilidades, no campo da saúde, que possam comprometer o pleno desenvolvimento escolar; VII) Promover a comunicação, encaminhamento e resolutividade entre escolas e unidades de saúde, assegurando as ações de atenção e cuidado sobre as condições de saúde dos estudantes; VIII) Atuar, efetivamente, na reorientação dos serviços de saúde para além de suas responsabilidades técnicas no atendimento clínico, para oferecer uma atenção básica e integral aos educandos e à comunidade. (BRASIL, 2011b, p.7).

O PSE tem como um de seus objetivos contribuir para a formação integral dos estudantes por meio de ações de promoção, prevenção e atenção à saúde, com vistas ao enfrentamento das vulnerabilidades que comprometem o pleno desenvolvimento de crianças e jovens da rede pública de ensino. Portanto, é primordial que as/os educandos sejam preparados/as sobre as atividades em saúde na escola, que serão desenvolvidas/realizadas, e não apenas avisados/as de sua ocorrência. Essa recomendação é pautada na necessidade de execução de um trabalho anterior regulado num contexto inter e multidisciplinar, de forma situada e legítima em sala de aula (seja numa aula de ciências, literatura, história, educação física, etc.), “[...] de maneira que a atividade em saúde a ser desenvolvida/realizada tenha sentido e esteja relacionada com o momento pedagógico ou conteúdo que os alunos estão trabalhando e interessados". (BRASIL, 2011b, p.14).

Nesse sentido é que se pensou como estratégia a criação do Projeto Formação de Jovens Protagonistas para o Projeto Saúde na Escola ou Saúde e Prevenção na Escola (PSE/SPE), por meio da metodologia de educação de pares almeja a valorização do/da jovem como protagonista na defesa dos direitos à cidadania e a saúde (BRASIL, 2011b);

Desse projeto resultou a publicação e distribuição do Guia Adolescentes e Jovens para a Educação entre Pares, que busca auxiliar no desenvolvimento de ações de formação para promoção da saúde sexual e saúde reprodutiva, a partir do fortalecimento do debate e da participação juvenil. Composto por oito fascículos o material aborda temas como: Sexualidade e saúde reprodutiva; Adolescências: juventudes e participação; Metodologias; Gêneros; Álcool e outras drogas; Raças e etnias; Prevenção das DST: HIV e AIDS e Diversidades sexuais.

Entendemos a importância da discussão de cada tema no âmbito educacional, porém como o princípio desse trabalho é discutir sobre a homofobia e diversidade sexual, 
vamos nos ater a debater apenas aquilo que se refere a diversidades sexuais e quiçá fazer algumas inferências sobre gêneros.

\section{Divergências}

No sentido estrito da palavra, divergência assume um caráter de afastamento na maneira de proceder ou de sentir, ou seja, algo em desacordo. Nesse aspecto observamos que entre os subprodutos resultantes de estratégias de cumprimento das diretrizes propostas pelos Programa BSH e SPE, denominados Kit anti-homofobia e Guia Adolescentes e Jovens para a Educação entre Pares, não há um deslocamento de objetivos, uma vez que ambos pretendem discutir questões relacionadas à cidadania, saúde, prevenção, mas principalmente o reconhecimento da (s) múltiplas identidade (s) assumida (s) ou não e da (s) diferença (s) impostas aos/as jovens L, G, B e Ts no cotidiano escolar.

Por discordância entendemos e fazemos a análise nesse estudo apontando ao referido kit anti-homofobia,

[...] a possibilidade real de difusão de um material dessa natureza, capaz de contribuir com a pluralização dos gêneros, isto é, capaz de contribuir com a produção de sentidos sobre gêneros e sexualidades que põem em risco a ordem sexual vigente, provocou a fúria dos fundamentalistas religiosos que tramam, tecem uma rede de intrigas e inverdades em torno do material. Uma das inverdades difundidas por esses sujeitos afirma que os vídeos que compõem o Kit informativo fazem apologia a homossexualidade. (SILVA, 2012, p.2).

A apresentação inicial do kit anti-homofobia gerou um desconforto para a comunidade LGBT e causou uma desconfiança quanto à finalidade e intencionalidade do seu conteúdo. Com indignação é que foram ouvidas as declarações do ex-secretário do Ministério da Educação, André Lázaro, ao fazer piada sobre o desenvolvimento do kit que o Governo pretendia entregar nas escolas, referindo-se a dúvida que tiveram na elaboração do material sobre a profundidade da língua durante um beijo lésbico. A contestação em torno de sua "[...] fala tem origem no momento em que discursava aos congressistas, representantes de entidades de apoio à confecção do material e elaboradores dos vídeos - componentes da Comissão de Direitos Humanos da Minoria (CDHM)" (BRANDÃO; SANTANA, 2011, p.172). 
Esse discurso instigou bancadas políticas evangélicas e sociedade civil a organizarem-se e agir de forma contrária à divulgação do kit anti-homofobia. Câmaras Legislativas se transformaram em cenários de repúdio ao projeto. A sociedade civil distribui pela rede mundial de computadores incontáveis pedidos de suspensão do kit gay. A imprensa midiática alardeava os fatos. No contexto destes embates adquire visibilidade alguns personagens legisladores chamando a atenção para os supostos perigos que o material pedagógico produzido pelo Ministério da Educação e Cultura (MEC) provocaria na educação e na sociedade brasileira, por fazer apologia à homossexualidade, induzir a pedofilia, incentivar a promiscuidade entre outros discursos realizados na mídia e Câmara de Deputados (BRANDÃO; SANTANA, 2011; GRESPAN; GOELLNER, 2011).

Diante de toda essa pressão, a Presidente Dilma Rousseff concordou que o material visual não possuía teor correto para ser apresentado a crianças e jovens e que o material fazia propaganda de orientação sexual, mesmo não tendo assistido ao material confirmado em seu discurso ${ }^{5}$. Defendendo a função do governo é apenas educar para que se evitem agressões e desrespeitos à diferença, não podendo interferir na vida particular dos sujeitos e nem propagar opções sexual na quarta-feira de 25 de maio de $2011 \mathrm{em}$ Brasília, sob determinação da Presidenta (BRANDÃO; SANTANA, 2011; GRESPAN; GOELLNER, 2011).

Com esse discurso, o Poder Executivo pôs termo a uma sucessão de debates e embates entre movimentos sociais vinculados à classe LGBT, as esferas de Poderes Legislativos e sociedade civil. Essas condutas demonstram a atuação das tradições elitistas que persistem através da distinção hierárquica entre alta cultura e cultura de massa, entre cultura burguesa e cultura operária, entre cultura erudita e cultura popular, entre aqueles que regem a política e os que são regidos politicamente (COSTA; SILVEIRA; SOMMER, 2003).

Ao contrário do que se sucedeu com o famigerado kit anti-homofobia o Guia Adolescentes e Jovens para a Educação entre Pares já chegou até às escolas da rede pública de ensino e pode ser usado como um material para subsidiar professores/as, educadores/as no tratamento da diversidade sexual e combate a LGBTfobia. Esses/as agentes poderão modular o conteúdo a ser trabalhado em sala de aula de acordo com a idade, com as regiões, com o interesse e até mesmo com as capacidades de cada um de se aprofundar naquele tema e promover uma discussão consistente (FURLANI, 2011).

${ }^{5}$ Disponível em: <http://www.youtube.com/watch?v=ESftwb6gkyc>. Acesso em: 14 abr. 2012. 


\section{Reticências}

O termo reticencias indica a supressão ou omissão voluntária de uma coisa que poderia ou deveria ter sido feita ou dita, nesse sentido vale considerar as palavras de Fernandes (2011b, grifo nosso): porque o "Kit de Combate à Homofobia" é gerador de tamanha reação? Em resposta fornecida pelo mesmo autor, o conflito entre a "oposição homofóbica ao Kit" e "governo e proponentes do Kit" pode ser traduzido como um conflito entre concepções cristãs (fundamentalistas) sobre a sexualidade humana e a posição dos movimentos sociais e o governo brasileiro de que a homofobia é degradadora da salubridade do ambiente escolar. Porém, esquece-se de atribuir a ela a responsabilidade pela evasão dos/as alunos/as vistos ou assumidos/as como LGBT provocada pela violência a que estes/as são submetidos na escola. (FERNANDES, 2011a, p.334).

Materiais de combate à homofobia foram publicados aos montes no governo anterior e continuam sendo publicados e distribuídos, não apenas pelo MEC e pelo governo federal, mas também por secretaria estaduais e municipais, universidades e ONG, como o caso do Guia Adolescentes e Jovens para a Educação entre Pares. O que está por detrás da polêmica do kit gay é o fortalecimento de posições conservadoras e fascistas de nossa sociedade e pelo contexto político que envolvia investigações a época sobre o então ministro da Casa Civil, Antônio Palocci. (FERNANDES, 2011b; BALESTERO, 2011).

Comungando dessa hipótese em entrevista ao Programa Sala de Notícias no Canal Futura, onde a discussão girava em torno da diversidade sexual na escola, Bortolini (2006) afirma que a suspensão do kit anti-homofobia:

Teve a ver com uma determinada conjuntura política na época e que, enfim, o kit foi usado como moeda de troca nesse jogo político [...] acho muito complicado porque vendo a Dilma, não só no veto ao kit, mas na fala dela depois reafirmando esse veto, dizendo que isso era uma questão de costumes, que não devia ser discutido na escola e etc. [...] eu acho que as pessoas não têm a noção da magnitude disso na escola, da repercussão disso na escola [...] se você tinha até aquele momento uma diretora que tava vendo situações de violência dentro da escola, que tava vendo um conflito gerado por essas questões dentro da escola, que tava [...] pensando se discutia ou não esse tema, depois de uma fala como essa, de um ato como esse do governo federal, essa professora que tava na dúvida tinha certeza que ela não tinha que fazer nada [...] isso provoca um mobilismo, um retrocesso, um medo de trabalhar essa questão, um medo de discutir essa questão muito forte. Inclusive dissemina essa desinformação de um material que ninguém viu, de um 
material que ninguém sabe quais são esses vídeos e que ninguém conhece e que acaba marcando outras questões, outros debates [...] tem uma série de materiais produzidos por universidades, por organizações, mas parece que o único material que existe pra discutir diversidade sexual é esse kit e é sobre esse kit que gira toda a discussão. (BORTOLINI, 2006, s./p., grifos nosso).

Se a suspensão do material refletiu na escola causando duvidas entre educadores/as, pesquisas realizada pela Reprolatina (MORÁGUEZ et al., 2011), UNESCO (2004), Abramovay (2009), Fundação Instituto de Pesquisas Econômicas (2009), Fundação Perseu Abramo (2009) comprovam que a escola, em particular, configura-se num lugar de opressão no qual sujeitos L, G, B e Ts vivem de maneiras distintas, situações delicadas de vulnerabilidade, negação, autoculpabilização e internalização da homofobia. Isso se faz com a participação ou omissão da própria escola, da família, sociedade civil e Estado (LOURO, 2009; FERRARI, 2009; JUNQUEIRA 2009; LIONÇO; DINIZ, 2009).

\section{Conclusão}

Fica evidente o esforço do Estado e sociedade organizada em priorizar a instituição escolar no desenvolvimento de políticas afirmativas e de inclusão para a diversidade sexual, já que é neste espaço que esses/as jovens passam por inúmeras formas de discriminações, agressões e rotulações, de maneira que os sujeitos vistos como diferentes ou desviantes são, muitas vezes, obrigados a abandonarem os estudos. (BORGES; MEYER, 2008).

No entanto, se o Governo Federal, devido às pressões políticas e sociais, recuou em relação à distribuição do kit anti-homofobia, pesquisas demostram que o ambiente escolar é altamente homofóbico e heteronormativo o que, por si só, já justificaria a necessidade da produção de materiais didáticos que pudessem colocar esses temas em xeque. (GRESPAN; GOELLNER, 2011).

Ao fim de toda essa polêmica ficará sempre uma indagação difícil de ser respondida: porque o kit anti-homofobia? Porém esse tipo de questionamento, nem a suspensão desse material poderá mais ser usada como justificativa ou recusa de discussão da temática sexual, combate a homofobia, ao sexismo e o respeito à(s) diversa (s) identidades assumidas por homens e mulheres LGBT, por educadores/as das instituições de ensino brasileiras, uma vez que para além de um kit anti-homofobia temos a nossa 
disposição incontáveis publicações, como no caso das estratégias do PSE que distribuiu recentemente para as entidades educacionais o Guia de Adolescentes e Jovens para a Educação entre Pares, composto por oito fascículos intitulados e que entre eles contempla o assunto em questão.

Diante de tais evidências é manifesta a necessidade da implantação de estratégias de apoio e tolerâncias a (s) diferença (s). Porém compreendemos que a adoção de qualquer medida deve ser uma decisão conjunta, pois as políticas educacionais que têm por objetivo criar condições de mudanças conceituais, de atitudes e práticas precisam estar engendradas com o meio sociocultural no qual as pessoas, os/as profissionais e as/os docentes que serão abrangidos por essas ações, vivem. Para Junqueira (2009) as ações que não levam em consideração esses aspectos deseducam e afetam a formação de todos/as envolvidos/as, o prejuízo é geral, porém, alguns/mas são chamados/as a pagar uma conta bem mais alta por não terem seus direitos preservados.

\section{DIFFERENCES, CONGRUENCES AND ELLIPSIS: A COMPARATIVE ANALYSIS OF GOODS BETWEEN SCHOOL PROGRAMS AND WITHOUT HOMOPHOBIA HEALTH AND PREVENTION IN SCHOOLS}

ABSTRACT: Levels of disqualification to which thousands of LGBT youth and adults are subjected emerge in several instances as: church, politics, media, society, school, etc.., The school is characterized as a strategic implementation of educational policies. In this context actions arise as Program School without Homophobia and Health and Prevention in the School. As a fragment of a larger study aimed at Masters qualification, we bring the discussion byproducts arising from these programs titled: Kit antihomophobia and MEC Guide to Adolescent and Youth Peer Education, respectively. Both strategies have congruences, differences and reluctance among themselves. For this study we relied on the meaning of cultural studies and literary references produced on the subject, featuring literature. We conclude that the absence of material on the subject can no longer be justified in discussing sexual diversity and combat and prevent homophobia because if certain material was not distributed to schools, educators / the other publications may have already done.

KEYWORDS: Anti-homophobia kit. Guide for teens and youth peer education. School Project without Homophobia. Sexual diversity. Homophobia.

\section{REFERÊNCIAS}

ABRAMOVAY, M. Revelando tramas, descobrindo segredos: violência e convivência nas escolas. Brasília: Secretaria de Estado de Educação do Distrito Federal - SEEDF, 2009. 
AGREDA, R. F. El sueño del celta: ¿Vargas Llosa homofóbico? Letralia Tierra de Letras, Venezuela, ano 17, n.273, 2012.

ALTMANN, H. Orientação sexual em uma escola: recortes de corpo de gênero. Cadernos Pagu, Campinas, n.21, p.281-315, 2003.

ALTMANN, H. Orientação sexual nos Parâmetros Curriculares Nacionais. Estudos Feministas, Florianópolis, v.9, n.2, p.575-587, 2001.

BALESTERO, G. S. O direito à diversidade sexual no Brasil e os efeitos violentos do descaso do poder legislativo federal. Revista Espaço Acadêmico, Maringá, v.11, n.123, p.5-16, ago., 2011.

BORGES, Z. N.; MEYER, D. E. Limites de uma ação educativa na redução da vulnerabilidade à violência e à homofobia. Ensaio: Avaliação e Políticas Públicas Educacionais, Rio de Janeiro, v.16, n.58, p.59-706, 2008.

BORTOLINI, A. Diversidade sexual na escola. Programa Sala de Notícias. Produção de Paula Fontes, Sara Oliveira e Jaqueline Souza. Rio de Janeiro: Canal Futura, 2012, parte 2. (Comunicação oral). Disponível em: <http://www.youtube.com/watch?v=HnJgbLONzU\&list=UU2mmP8ysfyko40KSn90x6Og>. Acesso em: 25 dez. 2012.

BRANDÃO, P. F.; SANTANA, T. O "kit gay": na saúde e na educação um kit de polêmicas. Caos - Revista Eletrônica de Ciências Sociais, Campina Grande, n.18, p.167-176, set., 2011.

BRASIL. Ministério da Saúde. Secretaria de Vigilância em Saúde. Departamento de DST, Aids e Hepatites Virais. Adolescentes e jovens para uma educação entre pares: diversidades sexuais. Brasília: Ministério da Saúde, 2011a. v.8.

Departamento de Atenção Básica. Instrutivo PSE / Ministério da Saúde. Departamento de Atenção Básica. Passo a Passo PSE - Programa Saúde na Escola: tecendo caminhos da intersetorialidade. Brasília: Ministério da Saúde, 2011 b.

. Secretaria de Educação Continuada, Alfabetização e Diversidade. Gênero e diversidade sexual na escola: reconhecer diferenças e superar preconceitos. Brasília: MEC/SECAD, 2007.

Conselho Nacional de Combate à Discriminação. Brasil sem homofobia: Programa de combate à violência e à discriminação contra GLTB e promoção da cidadania homossexual. Brasília: Ministério da Saúde, 2004.

. Secretaria de Planejamento e Investimentos Estratégicos. Plano de Gestão do PPA 2004-2007. Brasília: Ministério do Planejamento, 2004b.

COSTA, M. V.; SILVEIRA, R. H.; SOMMER, L. H. Estudos culturais, educação e pedagogia. Revista Brasileira de Educação, Rio de Janeiro, n.23, p.36-61, mai./ago., 2003. 
DINIS, N. F. Homofobia e educação: quando a omissão também é signo de violência. Educar em Revista, Curitiba, n.39, p.39-50, jan./abr., 2011.

DOVIDIO, J. F.; GLICK, P.; RUDMAN, L. A. Introduction: reflecting on the nature of prejudice: fifty years after Allport. In: DOVIDIO, J. F.; GLICK, P.; RUDMAN, L. A. (Ed.). On the nature of prejudice: fifty years after Allport. Malden: Blackwell Publishing, 2005. p.1-16.

FERNANDES, F. B. M. A agenda anti-homofobia na educação brasileira (20032010). 2011. 422f. Tese (Doutorado em Ciências Humanas) - Universidade Federal de Santa Catarina, Florianópolis, 2011a.

. Estado, sexualidade e educação: a questão do kit anti-homofobia. In: GRUPO DE DIVERSIDADE SEXUAL DA UDESC, Florianópolis, 2011b. (Comunicação oral). Disponível em:

<http://www.youtube.com/watch?v=_P3Rn0tfttg\&list=PL7309D62FFAB43733>. Acesso em: 23 dez. 2012

FERRARI, A. Reflexões sobre a homofobia na escola. In: CASAGRANDE, L. S.; LUZ, N. S.; CARVALHO, M. G. (Org.). Igualdade na diversidade: enfrentando o sexismo e a homofobia. 1. ed. Curitiba: Ed. da UTFPR, 2011. p.69-89.

FOUCAULT, M. Vigiar e punir: nascimento da prisão. Tradução Raquel Ramalhete. 29. ed. Petrópolis: Vozes, 2004.

FUNDAÇÃO INSTITUTO DE PESQUISAS ECONÔMICAS. Projeto de estudo sobre ações discriminatórias no âmbito escolar, organizadas de acordo com áreas temáticas, a saber, étnico-racial, gênero, geracional, territorial, necessidades especiais, socioeconômica e orientação sexual. São Paulo: FEA/USP, 2009.

FUNDAÇÃO PERSEU ABRAMO. Diversidade sexual e homofobia no Brasil.

Intolerância e respeito às diferenças sexuais. São Paulo: Fundação Perseu Abramo, 2009.

FURLANI, J. Estado, sexualidade e educação: a questão do kit anti-homofobia. In: GRUPO DE DIVERSIDADE SEXUAL DA UDESC, Florianópolis, 2011.

(Comunicação oral). Disponível em: <http://www.youtube.com/watch?v=_P3Rn0tfttg >. Acesso em: 23 dez. 2012.

GATTI, B. A. Formação continuada de professores: a questão psicossocial. Cadernos de Pesquisa, São Paulo, n.119, p.191-201, jul., 2003.

GRESPAN, C. L.; GOELLNER, S. V. Querem, na escola, transformar seu filho de 6 a 8 anos em homossexual: sexualidade, educação e a potência do discurso heteronormativo. Revista FACED, Salvador, n.19, p.103-122, jan./jun., 2011.

HALL, S. A identidade cultural na pós modernidade. Tradução Tomaz Tadeu da Silva; Guacira Lopes Louro. 11. ed. Rio de Janeiro: DP\&A, 2006.

Quem precisa da identidade? In: SILVA, T. T. (Org.). Identidade e diferença: a perspectiva dos estudos culturais. 7. ed. Petrópolis: Vozes, 2007. p.103-133. 
INCLUSIVE. Nota Oficial sobre o Projeto escola sem homofobia. [S.1.], 2011. Disponível em: <http://www.inclusive.org.br/?p=18368>. Acesso em: 3 nov. 2012.

JUNQUEIRA, R. D. Aqui não temos gays nem lésbicas: estratégias discursivas de agentes públicos ante medidas de promoção do reconhecimento da diversidade sexual nas escolas. Revista Bagoas, Caicó, n.4, p.171-190, 2009.

O reconhecimento da diversidade sexual e a problematização da homofobia no contexto escolar. In: SEMINÁRIO CORPO, GÊNERO E SEXUALIDADE: discutindo práticas educativas, 3., 2007, Rio Grande. Anais... Rio Grande: Ed. da FURG, 2007.

LIONÇO, T.; DINIZ, D. Qual a diversidade sexual dos livros didáticos brasileiros? In: LIONÇO, T.; DINIZ, D. (Org.). Homofobia e educação: um desafio ao silêncio. Brasília: Ed. da UnB, 2009. p.9-15.

LOURO, G. L. Heteronormatividade e homofobia. In: JUNQUEIRA, R. D. (Org.). Diversidade sexual na educação: problematizações sobre a homofobia nas escolas. Brasília: Secad/MEC, 2009. p.85-95.

LUNA, S. V. Planejamento de pesquisa: uma introdução. 2. ed. São Paulo: EDUC, 1999.

MORÁGUEZ, A. J. D. et al. Projeto escola sem homofobia: componente de pesquisa: estudo qualitativo sobre a homofobia no ambiente escolar em 11 capitais brasileiras. Reprolatina: soluções inovadoras em saúde sexual e reprodutiva. [S.1.], 2011. Disponível em: <http://www.reprolatina.org.br/site/html/atividades/downloads/

escola_sem_homofobia/Relatorio_Tecnico_Final.pdf>. Acesso em: 2 mai. 2013.

MELLO, L. et al. Para além de um kit anti-homofobia: políticas públicas de educação para a população LGBT no Brasil. Revista Bagoas, Caicó, n.7, p.99-122, 2012.

OLIVEIRA JÚNIOR, I. B.; LIMA, E. S.; MAIO, E. R. M. Heterossexismo e sua tenacidade nas políticas educacionais, práticas docentes e aprendizagem. ECS Educação Cultura e Sociedade, Sinop, v.2, n.2, p.134-147, jul./dez., 2012.

PINHEIRO, L. O que é homofobia. [S.1.], 2012. Disponível em:

<http://www.unilasalle.org/revistas/index.php/Conhecimento_Diversidade/index >. Acesso em: 24 dez. 2012.

SAYÃO, Y. Orientação sexual na escola: os territórios possíveis e necessários. In: AQUINO, J. G. Sexualidade na escola: alternativas teóricas e práticas. São Paulo: Summus, 1997. p.107-118.

SILVA, T. T. A produção social da identidade e da diferença. In: SILVA, T. T. (Org.). Identidade e diferença: a perspectiva dos estudos culturais. 7. ed. Petrópolis: Vozes, 2007. p.73-102.

SILVA, Z. P. Bafão do kit gay: análise do discurso da militância LGBT. Estudos Feministas, Bahia, jan./jun., 2012. 
SOUSA FILHO, A. A resposta gay. In: BARROS JUNIOR, F. O.; LIMA, S. O. (Org.).

Homossexualidades sem fronteiras: olhares. Rio de Janeiro: BookLink, 2007. p.11-35.

v.1.

Orientação sexual: construção política do desejo, ou crítica da substancialização. [S.1.], 2013b. Disponível em:

<http://www.cchla.ufrn.br/alipiosousa/index_arquivos/ARTIGOS\%20ACADEMICOS/A RTIGOS_PDF/Orientacao\%20sexual\%20-

$\% 20 a \% 20$ construcao\%20politica\%20do\%20desejo.pdf>. Acesso em: 7 jan. 2013.

SOUSA FILHO, A. A política do conceito: subversiva ou conservadora? - crítica à essencialização do conceito de orientação sexual. Revista Bagoas, Caicó, n.4, p.59-77, 2009.

UNESCO. O perfil dos professores brasileiros: o que fazem, o que pensam, o que almejam. São Paulo: Moderna, 2004. 